\title{
A CRIANÇA ESTRANGEIRA: UMA ANÁLISE DE BOITEMPO
}

Josyane Malta Nascimento

Doutoranda UFJF

\section{RESUMO}

Este trabalho dedica-se a uma reflexão sobre a hospitalidade a partir do pensamento de Jacques Derrida e das memórias de infância do poeta Carlos Drummond de Andrade, especialmente em sua obra poética Boitempo. Pretende-se refletir com poemas dessa obra a relação entre a criança e o adulto como categorias de hóspede e hospedeiro.

\section{PALAVRAS-CHAVE}

Boitempo, Drummond, Derrida, hospitalidade

O pensamento, o poema e a literatura têm a responsabilidade inventiva da criação e por isso são também instrumentos de resistência e dissidência. A categoria de análise aqui proposta, a criança, engendra na obra poética e memorialística de Carlos Drummond de Andrade, Boitempo, a responsabilidade do ato criativo: de deslocar-se, saber dar a palavra ao Outro, ser o Outro e enunciar-se em garantia da alteridade.

Jacques Derrida nos dá essa lição em todo o conjunto de sua obra. Por isso, pretende-se refletir sobre algumas questões que o filósofo da desconstrução nos tem a dizer. A leitura proposta parte do livro Anne Dufourmantelle convida Jacques Derrida a falar da hospitalidade.

A categoria teórica estrangeiro, nessa obra do argelino, é construída ampla e metaforicamente em sua discussão com Anne Dufourmantelle, entendendo-se que se trata de uma condição marginal de um indivíduo deslocado politicamente e/ou socialmente em seu espaço de convivência. Nesse caso, se pensarmos no poeta Drummond, além de se nomear gauche, ele também assumiu semelhante posição nos anos de 1968, tempos de repressão no Brasil. Sua poesia não poderia ser diferente. A representação da criança, em Boitempo, oferece leituras amplas dessas relações de repressão que culminam no desajustamento de si em seu meio social. Desse modo, a 
condição da criança é semelhante à do estrangeiro, uma vez que ela ocupa um lugar deslocado em relação ao Outro.

No poema "Banho de bacia”, de Menino antigo, é possível perceber a voz da criança em confronto com a do adulto, cujo discurso possibilita que o entendamos como autoritário. O menino, ao se preparar para seu banho de bacia, discute com um adulto sobre o fato de a água estar muito quente. O adulto responsável pelo banho da criança, porém, não considera a água que esteja "pelando”:

No meio do quarto a piscina móvel tem o tamanho do corpo sentado. Água tá pelando! mas quem ouve o grito deste menino condenado ao banho? Grite à vontade.

Se não toma banho não vai passear.

E quem toma banho em calda de inferno? Mentira dele, água tá morninha, só meia chaleira, o resto é de bica.

Arrisco um pé, outro pé depois. Vapor vaporeja no quarto fechado ou no meu protesto.

A água se abre à faca do corpo e pula, se entorna em ondas domésticas.

Em posição de Buda me ensabôo, Resignado me contemplo.

O mundo é estreito. Uma prisão de água envolve o ser, uma prisão redonda.

Então me faço prisioneiro livre.

Livre de estar preso. Que ninguém me solte

deste círculo de água, na distância

de tudo mais. $\mathrm{O}$ quarto. $\mathrm{O}$ banho. $\mathrm{O}$ só.

O morno. $\mathrm{O}$ ensaboado. O toda-vida.

Podem reclamar, podem arrombar a porta. Não me entrego ao dia e seu dever. ${ }^{1}$

Ao refletirmos sobre o "grito" do menino que não é ouvido, percebemos que a voz dessa criança é excluída. Sua voz não é ouvida pelo adulto, que se apresenta como reflexo dos discursos de poder. Ninguém ouvirá essa criança. Sua voz não conta e não é tampouco considerada. O menino, então, aceita “a prisão de água”, mas não se sente completamente prisioneiro, na verdade. Vejamos por quê.

\footnotetext{
${ }^{1}$ ANDRADE. Boitempo, p. 937-938.
} 
“O mundo é estreito”, fala o menino. Talvez poderíamos ousar tentar uma hipótese de interpretação: não queria esse menino dizer que o seu mundo é estreito? "É uma prisão de água que envolve o ser”, diz ele. Se quisermos tentar compreender essa “prisão de água”, é preciso que não nos limitemos a entendê-la apenas no plano literal. A prisão de água é a vida do menino, o “ser menino”, não a vida dos outros. A criança é prisioneira, sim. Mas "prisioneira livre” por estar presa em seu próprio mundo, distante do mundo do outro dominante, à margem do discurso do adulto, hegemônico. O “só": a solidão de sua voz calada pelo discurso do Outro. Esse Outro, o adulto, é aquele que a criança questiona, é a voz da autoridade. Mas seria mesmo a criança, como estrangeira, que questiona o Outro?

Essa é exatamente a pergunta que inicia a quarta sessão de entrevistas proferida por Jacques Derrida a Dufourmantelle, em 10 de janeiro de 1996, e que abre o livro: “A questão do estrangeiro não seria uma questão de estrangeiro? Vinda do estrangeiro?”2 Segundo Derrida, o estrangeiro seria a própria questão:

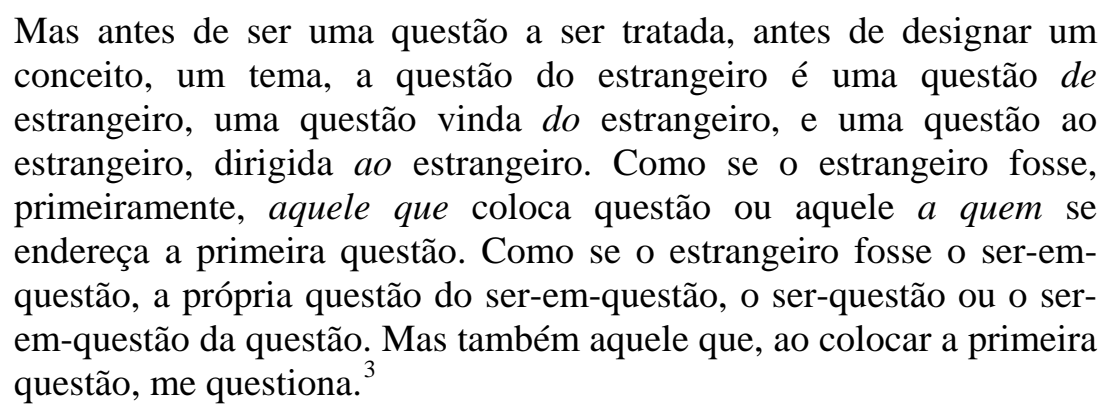

Derrida vê o estrangeiro acometido por uma série de atributos e funções concomitantes. O estrangeiro é aquele que é questionado; ao mesmo tempo, ele, questionado pelo Outro, traz a questão; e enfim, o estrangeiro também pode ser aquele que questiona o outro, já que traz a questão consigo. E ao questionar o Outro, o dono da casa, o estrangeiro comete, imediatamente, devido a sua própria existência, a dissidência.

A criança, vista a partir de uma perspectiva marginal, ao questionar o adulto, ao mesmo tempo em que lhe pede a hospitalidade, pode também ser questionada por ele, tornando-se assim o problema em questão e trazendo consigo a própria questão. Isso acontece porque a criança torna-se capaz de, querendo ou não, tirar o Outro do

\footnotetext{
${ }^{2}$ DERRIDA. Anne Dufourmantelle convida Jacques Derrida a falar Hospitalidade, p. 5.

${ }^{3}$ DERRIDA. Anne Dufourmantelle convida Jacques Derrida a falar Hospitalidade, p. 5. (grifos do autor).
} 
seu lugar e função de hospedeiro e recolocá-lo como hóspede. O adulto arrisca-se, portanto, a perder a sua condição privilegiada de detentor do poder e, por isso mesmo, ele trate a criança como margem e a situe em seu devido lugar.

Estrangeira em sua própria casa, a criança nos poemas de Boitempo torna-se o objeto em questão no imediato momento em que ela se mostra como diferente do Outro. Segundo Derrida, o estrangeiro é quem "sacode o dogmatismo ameaçador do logos paterno". ${ }^{4}$ Sendo ele também mero "visitante” ou aprendiz de uma determinada cultura, o estrangeiro questiona a autoridade do Pai, o detentor do poder, que é o “'dono do lugar', do poder de hospitalidade”. ${ }^{5}$

Ao questionar e ao mesmo tempo ser a questão, o estrangeiro subverte as leis e traz consigo o desvio da norma ativo e destruidor. A condição "estrangeira” da criança confere a ela um discurso contra ao da autoridade, ainda que enunciado deslocadamente em relação ao Outro, mesmo falando uma língua que não seja a sua, mas daqueles que detêm o poder da hospitalidade:

(...) o estrangeiro é, antes de tudo, estranho à língua do direito na qual está formulado o dever de hospitalidade, o direito ao asilo, seus limites, suas normas, sua polícia, etc. Ele deve pedir a hospitalidade numa língua que, por definição, não é a sua, aquela imposta pelo dono da casa, o hospedeiro, o rei, o senhor, o poder, a nação, o Estado, o pai, etc. ${ }^{6}$

Derrida utiliza exemplos da Antiguidade Clássica. A Apologia de Sócrates serve como ilustração para se mostrar que muitas vezes a língua da autoridade é desconhecida. Não é necessário que se fale exatamente, literalmente, a língua do Outro. Como aconteceu com Sócrates, pode-se ser estrangeiro em seu próprio lugar. Como, então, condenar um estrangeiro? Como impor que ele fale uma língua desconhecida? Isso é hospitalidade? Haveria hospitalidade sem o estrangeiro?

Estes lhe impõem a tradução em sua própria língua, e esta é a primeira violência. A questão da hospitalidade começa aqui: devemos pedir ao estrangeiro que ele compreenda, que fale nossa língua, em todos os sentidos do termo, em todas as extensões possíveis, antes a fim de poder acolhê-lo entre nós? Se ele já falasse a nossa língua (...) o

\footnotetext{
${ }^{4}$ DERRIDA. Anne Dufourmantelle convida Jacques Derrida a falar Hospitalidade, p. 7.

${ }^{5}$ DERRIDA. Anne Dufourmantelle convida Jacques Derrida a falar Hospitalidade, p. 7.

${ }^{6}$ DERRIDA. Anne Dufourmantelle convida Jacques Derrida a falar Hospitalidade, p. 15 (grifos meus).
} 
estrangeiro continuaria sendo um estrangeiro e dir-se-ia (...) em hospitalidade? ${ }^{7}$

Se a imposição cultural é a condição para que o estrangeiro seja aceito, não se pode, então, falar em hospitalidade. Pois segundo Derrida, o estrangeiro é alguém que se serve do que o Outro lhe oferece. Se para que haja alguma hospitalidade é necessário que se fale uma mesma língua ou que ambos sejam culturalmente compatíveis, então não poderia haver hospitalidade.

O que se quer com esses pontos abordados na obra do argelino é considerar que a criança, podendo também ser considerada estrangeira em seu mundo, só terá hospitalidade se enunciar na língua dos “donos da casa”. Porém, ela - a língua da criança - não é compreendida pela autoridade adulta. Ela enuncia-se a partir de uma linguagem - metaforicamente - que o adulto não compreende, pois a sua ótica é diferente daquela que se quer imposta pela ordem a ser estabelecida pelo poder. $\mathrm{O}$ adulto, ao impor-se culturalmente, não oferece nenhuma hospitalidade à criança, porque fazê-la sua hóspede é perigoso para ele, que corre o risco de perder a sua casa, o seu lugar, o seu domínio. Afinal, quem está no poder não quer sair de seu “posto”, pois dar a palavra ao Outro é arriscar a perder seu espaço privilegiado para ele.

O poema “Os velhos”, de Boitempo, ilustra a questão do estrangeiro discutida por Jacques Derrida:

Todos nasceram velhos - desconfio.

Em casas mais velhas que a velhice, em ruas que existiram sempre - sempre!

assim como estão hoje e não deixarão nunca de estar: soturnas e paradas e indeléveis mesmo no desmoronar do Juízo Final. Os mais velhos têm 100, 200 anos e lá se perde a conta. Os mais novos dos novos, não menos de 50 - enorm'idade. Nenhum olha para mim.

A velhice o proíbe. Quem autorizou existirem meninos neste largo municipal?

Quem infringiu a lei da eternidade que não permite recomeçar a vida? Ignoram-me. Não sou. Tenho vontade de ser também um velho desde sempre. Assim conversarão comigo sobre coisas seladas em cofre de subentendidos

\footnotetext{
${ }^{7}$ DERRIDA. Anne Dufourmantelle convida Jacques Derrida a falar Hospitalidade, p. 15.
} 
a conversa infindável

de monossílabos, resmungos,

tosse conclusiva.

Nem me vêem passar. Não me dão confiança.

Confiança! Confiança!

Dádiva impensável

nos semblantes fechados,

nas felpudas redingotes,

nos chapéus autoritários,

nas barbas de milênios.

Sigo, seco e só, atravessando

a floresta de velhos. ${ }^{8}$

Como na maioria dos poemas de Boitempo, a criança é quem fala suas impressões sobre o mundo e o seu entorno. Esse espaço é a fazenda, a casa patriarcal e todo o conjunto de características de um lugar onde o menino sente-se deslocado.

O espaço composto por identidades (a)diversas é fisicamente compartilhado pelo menino e aqueles a quem ele chama de "os velhos". Mas culturalmente, a criança está deslocada e parece não falar a mesma língua que os “outros”. Nenhum deles fala com o menino e sua presença parece quase sempre ser indesejada: “Quem autorizou / existirem meninos neste largo municipal?”`9 A criança “não é”, não tem vontade: mas ao ser incomodada, ela também gera incômodos aos donos do lugar. A criança é, portanto, marginalizada, ainda que queira ser velha para poder compartilhar da mesma língua, pois “assim conversarão / comigo sobre coisas”. ${ }^{10}$ Os mais velhos não dão confiança ao menino “confiança! Confiança!” 11 Ou poderíamos traduzir como "hospitalidade”? Uma “dádiva impensável”. 12

Nem a criança e nem o adulto compartilham a mesma língua. Como Derrida observou: "No sentido amplo, a língua, aquela com a qual se dirige ao estrangeiro ou com a qual se ouve, é o conjunto da cultura, são os valores, as normas, as significações que habitam a língua.” ${ }^{313}$ Ser estrangeiro, portanto, não é apenas ser de espaços físicos e/ ou linguísticos distintos, mas, antes, é preciso que haja aspectos identitários notoriamente diferentes de ambas as partes, que haja uma situação de deslocamento, uma não adequação ao “Outro” consoante imbricações fortemente culturais:

\footnotetext{
${ }^{8}$ ANDRADE. Boitempo, p. 1.073-1.074.

${ }^{9}$ ANDRADE. Boitempo, p. 1.073.

${ }^{10}$ ANDRADE. Boitempo, p. 1.073.

${ }^{11}$ ANDRADE. Boitempo, p. 1.073.

${ }^{12}$ ANDRADE. Boitempo, p. 1.073.

${ }^{13}$ DERRIDA. Anne Dufourmantelle convida Jacques Derrida a falar Hospitalidade, p. 15.
} 
Sob determinados aspectos, posso ter mais em comum com um burguês intelectual palestino, cuja língua eu não falo, do que com determinado francês que, por tal ou qual razão social, econômica ou outra, me parecerá sob tal ou qual relação, mais estrangeiro. ${ }^{14}$

A representação da criança nos poemas de Boitempo possibilita a inserção dessa obra de Drummond no debate acerca de condições marginais representadas pela literatura e que refletem a importância do papel dos estudos de crítica da cultura. Pensar a figura da criança, em Boitempo, sob essa ótica do estrangeiro, possibilitou percebê-la como discurso subjugado por uma espécie de imposição cultural. Dessa forma, a criança não tendo nenhuma escolha, senão a de obedecer à ordem estabelecida, rende-se às condições impostas. Porém, exatamente por ser ela estrangeira - uma vez que é culturalmente incompatível com o adulto - ela questiona o Pai. Pois é a criança ao mesmo tempo quem carrega a questão, o próprio “ser-em-questão”, e é ela quem subverte a ordem ao questionar a brutal imposição da norma. Um desvio ativo, fértil como sempre pudemos ler nos grandes poemas de Drummond: o gauche que está à margem espiando, questionando e, dessa forma, subvertendo os padrões impostos ao oferecer discursos culturais alternativos.

Em situação análoga, também o intelectual, em especial o latino-americano, é aquele quem dispõe da questão, é aquele que subverte a ordem homogeneizante ao apresentar-se como discurso alternativo, deslocado e diferente do Outro, quiçá de sua metrópole, para usar um termo da colonização. E Drummond cria um discurso que vai além da mera representação: o discurso de memória é um modo de inscrever-se como Outro, um Outro subjetivo, único e particularíssimo. É uma alternativa discursiva num momento de repressão, num tempo de homogeneização identitária dos discursos culturais. Enunciar-se como Outro, destacar-se dos demais é revelar-se estrangeiro de seu mundo, e ser estrangeiro é colocar-se como questão, questionar, e sobretudo subverter e ser dissidente dos sistemas políticos de opressão e repressão cultural. Por fim, arriscar-se também a ser questionado pelo Outro, atacado pelo Outro. E esse é um risco que o intelectual latino-americano tem a tarefa ética de correr e aceitar.

\section{ABSTRACT}

This article aims at reflecting about hospitality, according to Jacques Derrida, in the memories of childhood as found in the poet Carlos Drummond de Andrade,

\footnotetext{
${ }^{14}$ DERRIDA. Anne Dufourmantelle convida Jacques Derrida a falar Hospitalidade, p. 15.
} 
especially in his poetic work Boitempo. The poems that make up this poetic work will serve as basis for the analysis between the child and the adult as categories in the manner of guest and host.

\section{KEYWORDS}

Boitempo, Drummond, Derrida, hospitality

\section{REFERÊNCIAS}

ANDRADE, Carlos Drummond de. Boitempo. In: Poesia completa. Rio de Janeiro: Nova Aguilar, 2003.

DERRIDA, Jacques. Anne Dufourmantelle convida Jacques Derrida a falar Hospitalidade. Trad. Antonio Romane. São Paulo: Escuta, 2003. 